\title{
Relationship between anthropometric, physiological and physical characteristics with success of female taekwondo athletes
}

\author{
Hamid ARAZI ${ }^{1}$, Zahra HOSSEINZADEH ${ }^{2}$, Mani IZADI ${ }^{1}$ \\ ${ }^{1}$ University of Guila, Department of Exercise Physiology, Faculty of Sport Sciences, Rasht, Iran. \\ 2 Islamic Azad University, Department of Sport Sciences, Faculty of Humanities Sciences, Rasht Branch, Rasht, Iran. \\ ${ }^{1}$ University of Guilan, Department of Exercise Physiology, Faculty of Sport Sciences, Rasht, Iran. \\ Address Correspondence to H. Arazi, e-mail: hamidarazi@yahoo.com
}

\begin{abstract}
The aim of this study was to investigate the relationship between anthropometric, physiological and physical characteristics with success of elite female taekwondo athletes. Forty subjects were selected from elite female taekwondo athletes who won medals in regional and national championships. Individual information forms were completed. The mean age, height and body mass index of subjects were $17.84 \pm 3.67$ years, $167.56 \pm 6.92 \mathrm{~cm}$ and $19.12 \pm 2.45 \mathrm{~kg} / \mathrm{m}^{2}$ respectively. All subjects were assessed for height, weight, lengths, girths, body mass index, waist-to-hip ratio and skin-fold thickness. Percentage of body fat was calculated from the sum of 3 site measurements of skin-fold thickness. Aerobic and anaerobic power were also calculated using by cooper and Sargent vertical jump tests respectively and then by placing into the standard recommended equations. Speed, agility, muscular endurance and flexibility were assessed using by $36 \mathrm{~m}$ sprint, $4 \times 9 \mathrm{~m}$ shuttle run, push-ups and sit-andreach tests respectively. From all of anthropometric, physiological and physical characteristics, anaerobic and aerobic power, body mass index and fat percentage, speed and agility were significantly related to success and had more importance for taekwondo athletes. Thus, these characteristics have a major effect on taekwondo specially, in championship goals and should be considered in talent identification and training planning of this sport.
\end{abstract}

Keywords: Success, taekwondo, anthropometry, bio-motor characteristics.

\section{INTRODUCTION}

Independent from sport type, having physical abilities such as anthropometric and physiological characteristics is a prerequisite to success against any competition or tournament. Knowing the mentioned characteristics is one of the determinant factors affecting athletes' performance. Being aware of these characteristics is an important issue for comparing an athlete's results to his previous achievements as well as other athletes, finding the weak points and correct them and finally, basic and accurate training planning in order to gain maximal results and to achieve determined goals (6).

According to the studies carried out in this field, elite athletes in each sport have special anthropometric and physiological features which result in their success in sport events and competitions (3). From the last decades, the assessment of anthropometric and physiological features is implemented by coaches. In few sports, some of features are more important in compared to some other features, which, these important features may be no important in some other sports. Moreover, these features may have close relationship with success in that sport.

On the other hand, the possibility for identifying and screening the talented athletes in sport is more obtained through gaining more information about this relationship. Moreover, individuals who have higher potential will able to achieve better results in competitions using special trainings in which the priorities of athletes' physical demands are considered (18). In different sports' continuum, 
athletes competing in combat sports require high levels of technique, tactic and physical fitness specially strength, aerobic fitness, muscular power and speed. Combat sports are classified according to their techniques and rules and, subsequently, their physical demands are required to achieve top levels in each sport are also different $(7,24)$.

Taekwondo is a combat sport which its origin goes back to the old Korean martial arts and 1500 years ago. Nowadays, taekwondo is practiced by numerous athletes in 140 countries around the world and 120 nations became official members of world taekwondo federation (WTF). Considerable development of taekwondo as a combat sport began with the constitution of world taekwondo federation (WTF) in 1973. This sport achieved the Olympic official membership in 2000 Sydney Olympic Games $(2,13,14)$.

Today, this martial art exists in two forms under the control of related organizations. One side, the world taekwondo federation stresses on sport performance and competition and other side the international taekwondo federation supports the traditional form of taekwondo. The traditional form of taekwondo includes fights with modified rules, breaking objects and showing the movements and techniques in special forms (14). Regularly, taekwondo competitions in accordance to the world taekwondo federation's goals are organized in three 2min rounds with 1-min intervals among rounds. The goal of competition is to overcome an opponent by gaining higher scores using kicks and punches on allowed areas in opponent's body or stop the match in the time reaching the technical knockout (5).

One of the significant aspects of taekwondo is its intermittent nature. For instance, after doing diverse and explosive kicks and punches, there is a time of low intensity actions for balancing time, as well as controlling the match. Thus, being aware of the relationship between kicks and punches and this period of time, also knowing athletes' physical requirements during the match is an important factor in the athletes' development pathway in taekwondo (19).

Regularly, the effectiveness of training in sport is assessed through the best sport performance or results. Hence, many researchers have tried to find the success factors in taekwondo. In this field, the majority of studies have explored the relationship between different characteristics and performance in taekwondo such as morphological $(17,20)$, biomechanical $(14,23)$, conditioning, physiological and psychological characteristics $(12,13,15,22)$. These studies indicated that the taekwondo athletes who have mesomorph structure, top levels of speed, strength, endurance and flexibility, shorter reaction time and accurate technique have also achieved better results in competitions.

Nevertheless, Markovic et al. (14) observed no significant difference between successful and unsuccessful female taekwondo athletes in flexibility. On the other hand, Newton et al. (16) and Markovic et al. (14) indicated that since the techniques in taekwondo have a ballistic nature and the majority of techniques in taekwondo are leg strikes (kicks), thus, it is expected that the explosive power of legs has a critical role in taekwondo athletes' performance. Whereas, some of other researchers such as Heller et al. (11) reported that explosive power of lower limbs can't properly categorize the performance of female taekwondo athletes. According to Gao et al. (9), the taekwondo athletes with ecto-mesomorph body have better chance to achieve excellent results in taekwondo competitions. Furthermore, Sadowski et al. (1) noted that medal winners had higher levels of body mass index (BMI) and lower amounts of body fat percentage, which demonstrates the importance of mesomorphic component of somatotype. But, some others believe that having some of anthropometric characteristics alone is not enough to achieve medal. Rather, success in taekwondo is a combination of physical features, talent, skill and technique $(6,9,11,21)$.

Hence, reviewing the past studies accentuates the importance of knowing the effective factors in success of taekwondo athletes in sport events. Whereas, the status of prioritize the characteristics as the highlighted factors in trainings and talent identification in this sport still remained unknown. Moreover, young girls of Guilan province in Iran have high potential for taekwondo and considerable population of these girls participate in national, regional and international competitions. The determination of factors related to success in female athletes as the delegations of talented female 
taekwondo athletes of country can be used in talent identification process of taekwondo. Furthermore, designing proper training programs and paying attention to physiological characteristics related to success by coaches can result in improvement of performance, athletes' more achievements and influential step in advancement of this sport. Thus, concerning some contradictory results and comments hereupon, as well as, the place of Guilan province female taekwondo athletes in national team and naturally, international competitions, the goal of the present study was to investigate the relationship between anthropometric, physiological and physical characteristics with success of elite female taekwondo athletes.

\section{MATERIALS \& METHODS}

The present study is descriptive and ex post facto design. Forty subjects were selected from elite female taekwondo athletes of Guilan province. These athletes won medals and at the time inviting for study were involved in taekwondo practice. After securing institutional ethical approval, the subjects were informed about test procedures and then were asked to provide written consent.

Their body weight was measured to the nearest $0.1 \mathrm{~kg}$ using Korona scale (made in Germany), and Seca 206 stadiometer was used to measure their height to the nearest $0.1 \mathrm{~cm}$. Body mass index was calculated by dividing weight by height squared ( $\mathrm{kg} / \mathrm{m}^{2}$ ). Skin-folds thickness (Triceps, Suprailiac and Thigh) were measured using Lafayette caliper (made in USA) and then body fat percentage was calculated through Jackson and Pollock equation (1978). All the measurements were performed on the right side of the body and at the same time approximately. Furthermore, the measurements of waist and hip circumference, waist to hip ratio, as well as, sitting height, upper limbs, lower limbs, forearm and calf length were performed using standard methods $(5,8)$.

In this study, Cooper test was used to determine maximal aerobic power. The subjects were asked to run with possible speed and $\mathrm{VO}_{2 \max }$ was estimated using below equation in order to assess aerobic power (25):

$$
\begin{gathered}
\mathrm{VO}_{2 \max }(\mathrm{ml} / \mathrm{kg} / \mathrm{min})=[(\text { distance } / 15-133) \times 0.172]+33.3 \\
\text { The anaerobic power (explosive form) was }
\end{gathered}
$$

determined using Sargent jump test. Following equation was used to calculate test results (25).

$$
P_{\text {peak }}(\mathrm{w})=78.5 \times \mathrm{VJ}(\mathrm{cm})+60.6-\text { mass }(\mathrm{kg})-15.3
$$

$\times$ height $(\mathrm{cm})-1.308$

Agility and speed were assessed by $4 \times 9 \mathrm{~m}$ shuttle run and $36 \mathrm{~m}$ sprint tests respectively. The results of these tests were recorded to the nearest 0.1 second (using $\mathrm{Q} \& \mathrm{Q}$ chronometer made in Japan). The leg press test was used to determine strength. Likewise, the push-ups and sit-and-reach tests were used to determine muscular endurance and flexibility, respectively.

The success level of athletes were scored in accordance to achieved medals in regional and national championships, namely, 100, 90 and 85 points and 80, 70 and 65 points were considered for 1 th to 3 th places in national and regional championships, respectively. The composite mean of resulted scores of each athlete was considered as her success score.

\section{Statistical analysis}

The normal distribution of data was determined through Kolmogrov-Smirnov test and the Pearson correlation coefficient was used to determine the relationship between anthropometric, physiological and physical characteristics with success. All statistical analyses were performed using SPSS version 20. $\quad \mathrm{P}<0.05$ was considered statistically significant.

\section{RESULTS}

Descriptive statistics of the present study including demographic and anthropometric characteristics, as well as physiological and physical characteristics are shown in tables 1 and 2, respectively. Moreover, the results of correlation coefficient are present in tables 3 and 4.

With the exception of body mass index and body fat percentage $(p \leq 0.05)$, no significant relationship was found between other anthropometric characteristics and success.

A positive and significant relationship $(\mathrm{p}<0.01)$ was found between aerobic power and success. Moreover, another physiological index of the present study (anaerobic power) was also positively and significantly related $(\mathrm{p}<0.01)$ to success. 
Table 1. Subjects' demographic and anthropometric characteristics.

\begin{tabular}{lc}
\hline Variables & Mean \pm SD \\
\hline Age(years) & $17.84 \pm 3.67$ \\
Height $(\mathrm{cm})$ & $67.56 \pm 6.92$ \\
Weight $(\mathrm{kg})$ & $55.23 \pm 7.12$ \\
Waist-to-hip ratio & $0.82 \pm 0.09$ \\
Body mass index $(\mathrm{kg} / \mathrm{m} 2)$ & $19.12 \pm 2.45$ \\
Body fat percentage & $18.75 \pm 3.98$ \\
Sitting height $(\mathrm{cm})$ & $59.98 \pm 4.51$ \\
Lower limbs length $(\mathrm{cm})$ & $55.16 \pm 4.59$ \\
Upper limbs length $(\mathrm{cm})$ & $34.52 \pm 3.40$ \\
Calf length $(\mathrm{cm})$ & $40.94 \pm 2.57$ \\
Forearm length $(\mathrm{cm})$ & $26.84 \pm 2.12$ \\
\hline
\end{tabular}

Table 2. Subjects' physiological and physical characteristics.

\begin{tabular}{lc}
\hline Variables & Mean $\pm \mathrm{SD}$ \\
\hline $\mathrm{VO}_{2 \max }(\mathrm{ml} / \mathrm{kg} / \mathrm{min})$ & $48.53 \pm 3.84$ \\
Anaerobic power(watt) & $6824.84 \pm 937.84$ \\
Speed(s) & $7.21 \pm 0.45$ \\
Agility $(\mathrm{s})$ & $11.62 \pm 1.62$ \\
Strength(kg) & $77.28 \pm 15.47$ \\
Muscular endurance(rep) & $35.16 \pm 2.88$ \\
Flexibility(cm) & $53.65 \pm 15.47$ \\
\hline
\end{tabular}

Table 3. The relationship between subjects' demographic and anthropometric characteristics with their success.

\begin{tabular}{lcc}
\hline Variables & $\mathrm{r}$ & $\mathrm{p}$ \\
\hline Age & 0.35 & 0.13 \\
Height & 0.16 & 0.50 \\
Weight & 0.24 & 0.28 \\
Waist-to-hip ratio & 0.33 & 0.17 \\
Body mass index & 0.58 & $0.02^{*}$ \\
Body fat percentage & 0.57 & $0.05^{*}$ \\
Sitting height & 0.38 & 0.11 \\
Lower limbs length & 0.38 & 0.11 \\
Upper limbs length & 0.10 & 0.69 \\
Calf length & 0.02 & 0.92 \\
Forearm length & 0.18 & 0.46 \\
\hline * Significant at level of $\mathrm{p} \leq 0.05$ & &
\end{tabular}

* Significant at level of $\mathrm{p} \leq 0.05$

Table 4. The relationship between subjects' physiological and physical characteristics with their success.

\begin{tabular}{lcc}
\hline Variables & $\mathrm{r}$ & $\mathrm{p}$ \\
\hline $\mathrm{VO}_{2 \max }$ & 0.87 & $0.001^{* *}$ \\
Anaerobic power & 0.78 & $0.001^{* *}$ \\
Speed & 0.64 & $0.004^{* *}$ \\
Agility & 0.59 & $0.01^{*}$ \\
Strength & 0.25 & 0.34 \\
Muscular endurance & 0.05 & 0.81 \\
Flexibility & 0.32 & 0.89 \\
\hline * Significant at level of $\mathrm{p}<0.05,{ }^{* *}$ Significant at level of $\mathrm{p}<0.01$
\end{tabular}

* Significant at level of $\mathrm{p}<0.05,{ }^{* *}$ Significant at level of $\mathrm{p}<0.01$
Among physical characteristics, negative and significant relationships were observed between speed $(p<0.01)$ and agility $(p<0.05)$ with success. Thus, no statistically significant relationship was found between strength, muscular endurance and flexibility with success.

\section{DISCUSSION}

The results of the present study showed that, with the exception of body fat percentage and BMI, there is no significant relationship between other anthropometric characteristics and success of taekwondo athletes. The mean BMI of female taekwondo athletes was 19.45 which was comparable to the results found in Czech and USA female taekwondo athletes $(8,25)$. Considering the significant relationship between BMI of Guilan province taekwondo athletes and their success, presumably, BMI can be used as a predictor anthropometric index of taekwondo athletes' success.

There is no significant relationship between taekwondo athletes' age and their success. In this regard, it can be noted that considering a limited range for age in the study resulted in no significant relationship between the taekwondo athletes' age with their success presumably, and through considering a more extensive range for age, it would be a possibility for different results.

The mean height and weight of Guilan female taekwondo athletes were $167.5 \mathrm{~cm}$ and $55.23 \mathrm{~kg}$, respectively, which were smaller than those reported in Czech $(168 \mathrm{~cm}$ and $62.3 \mathrm{~kg})$ and USA $(171.5 \mathrm{~cm}$ and $61.4 \mathrm{~kg})$ female taekwondo athletes $(4,25)$. The relationship between weight and success was no significant which agrees with Heller et al (1998). Considering the competitions in taekwondo are accomplished in definite weight categories and taekwondo competitors in each category have a same weight status, the result seems rationale. The relationship between height and calf length with success wasn't significant which agreed with Heller et al. (11). In this regard, it can be demonstrated that, although having taller structure and long legs can be an advantage for taekwondo athletes and result in their excellence in performing some kicks (such as Naeryo-Chagi and Dollyo-Chagi), nevertheless, successful performing of these techniques and obtaining scores by taekwondo athletes is affected by 
bio-motor characteristics such as reaction time, speed, agility, and explosive power specially in lower limbs and the mentioned anthropometric characteristics aren't alone determinant factors.

In this study, the mean body fat percentage of taekwondo athletes was 18.75 which was higher than those reported in Czech (15.4\%) and USA (12\%) female taekwondo athletes $(8,25)$. There is a significant and negative relationship between body fat percentage and success. In regard to this negative relationship should be noted that the athletes competing in national level should have a good physical status. In this manner, body fat percentage can be the factor negatively affecting the athletes' performance in top levels of this sport, because, the taekwondo competition requires agility and good physical fitness of athlete, hence, the lower body fat percentage can helps athlete's agility. In this field, Gao et al. (10) through surveying 30 Chinese taekwondo athletes illustrated that a proper somatotype is a well body structure, well-developed musculoskeletal system and low body fat percentage.

The results of the present study showed that both assessed physiological characteristics (aerobic and anaerobic power) significantly related to success. In this domain, Melhim et al. (15) after a period of taekwondo practice on 19 male adolescent taekwondo athletes concluded that anaerobic power $(28 \%)$ and anaerobic capacity $(5.61 \%)$ were increased and aerobic power remained changeless. Markovic et al. (14) demonstrated that the successful taekwondo athletes have higher speed and anaerobic threshold in comparison to their less successful counterparts. Considering the nature of taekwondo performance requires instantaneous, fast and explosive movements, this issue leads to change in profile of energy system and physiological features to the anaerobic system and power and speed performance, and the athletes in this sport aren't tended to aerobic profile (9). Furthermore, a reduced time of rounds, reduced size of match area, knockout by 12 points and increased corners for judging are the changes encouraging competitors to more explosive fight and gaining more scores (13). The results of this study showed that anaerobic power is an effective index in success of taekwondo athletes. But, on the other hand it can be noted that aerobic power of athletes should be also in a good status for sufficient and proper recovery among matches and training sessions (1). In regard to importance of aerobic power and body fat percentage in taekwondo competition mentioned above, Gao et al. (9) is the study indicating the relationship between these factors and their role on success of taekwondo athletes. They observed that body fat percentage of elite taekwondo athletes was lower than non-elite taekwondo athletes. They concluded that considering the importance of aerobic power in taekwondo competition, decreasing body fat percentage alongside increasing muscle mass is required in order to achieve top levels of $\mathrm{VO}_{2 \max }$.

Among physical characteristics, there is a significant relationship between speed and agility with success; but, no significant relationship was observed between flexibility, strength and muscular endurance with success which this non-significant relationship can be under effect of close levels of athletes' physical fitness. Considering one of determinant factors in effective and successful performing of taekwondo techniques, as well as in precluding on time reaction by opponent is high levels of speed. Thus, it can be noted that this characteristic has a major role in success of taekwondo athletes. Speed is more a genetic factor in comparison to the factors is affected by training, and genetic endowment has a major role in speed and agility of athletes. Hence, speed can be considered as a predominant characteristic in selection and talent identification of taekwondo athletes. A significant relationship was found between agility and success which concerning necessity of fast changing and reaction against opponent, we can find the importance of this factor in success of taekwondo athletes. These results agree with the results of Markovic et al. (14) about significant relationship between speed and success in taekwondo athletes, but doesn't agree with another results of their about non-significant relationship between agility and success. One of the reasons can be considered as the factor affected these results is presence of different tests were used in order to assess agility.

Concerning these results, it should be noted that success in taekwondo depends on various factors and regularly, successful taekwondo athletes have remarkable physiological characteristics. High speed for fast and on time performing of techniques, high levels of agility for changing the directions quickly, 
good reaction time for abrupt reaction against opponent's attacks, top levels of anaerobic power in order to fast, explosive and repetitive kicks and punches and finally, proper aerobic power for quick recovery between training sessions, competition rounds and between the matches are performed in a day, all are the important characteristics affecting taekwondo athlete performance which can have determinant role in success of these athletes.

Considering the results of the present study, among anthropometric characteristics a significant relationship was found alone between BMI and body fat percentage with success which among factors affected these results, we can allude to limited age range and close status of athletes' physical fitness. Another factor can be effective in this area is possible errors of judgment. Sport competitions and their results can also be under effect of judging errors and the athlete is more trained and has a better physical fitness, upon these errors may be remained failure to achieve medal and the results of study can suffer from this issue, because, in the present study achieving medal was alone considered as the criterion for assessing the success of taekwondo athletes.

Altogether, it can be stated that from all of the anthropometric, physiological and physical characteristics were assessed in this study, anaerobic and aerobic power, body mass index and fat percentage, speed and agility have more importance in success of taekwondo athletes. Based on the results of this study, considering physiological characteristics should be addressed by taekwondo coaches in their planning and designing training, wherefore these characteristics have a major effect on taekwondo specially, in championship goals.

\section{ACKNOWLEDGEMENTS}

The authors would like to thank the Taekwondo Federation of Islamic Republic of Iran and taekwondo athletes for their cooperation in this study.

\section{REFERENCES}

1. Anderson GS. A comparison of predictive tests of aerobic capacity. Canadian Journal of Sport Science, 1995; 11(4): 13-22.

2. Birrer RB. Trauma epidemiology in the Martial Arts: The result of an eighteen-year international survey. The American Journal of Sports Medicine, 1996; 24: S-72-79.

3. Bompa T. Periodization training for sport. Human Kinetics.1999.

Turk J Spart Exe 2016; 18(2): 69-75

๑ 2016 Faculty of Sport Sciences, Selcuk University
4. Bourgois J, Claessens AL, Janssens M, Renterghem BV, Loos R, Thomis M, Pilippaerts R, Lefevre J, Verijens J. Anthropometric characteristics of elite male junior rowers, British Journal of Sports Medicine. 2001; 34: 213-211.

5. Bridge CA, Santos VGF, Chaabene H, Pieter W, Franchini E. Physical and Physiological Profiles of Taekwondo Athletes. Sports Medicine, 2014; 44(6): 113-133.

6. Callan SD, Brunner DM, Devolve KL, Mulligan SE, Hesson J, Wilber RL, Kennedy JT. Physiological profiles of elite freestyle wrestlers. Journal of Strength and Conditioning Research, 2000; 14: $162-169$.

7. Chaabene H, Hachana Y, Franchini E, Mkaouer B, Chamari K. Physical and physiological profile of elite karate athletes. Sports Medicine, 2012; 42: 829-43.

8. Coppin E, Heath EM, Bressel E. Wingate anaerobic test reference values for male power athletes. International Journal of Sports Physiology and Performance, 2012; 1(3): 232-236.

9. Gao B, Zhao Q, Liu B. Measurement and evaluation on body composition and figure of taekwondo athlete. Journal of $\mathrm{Xi}^{\prime}$ an Institute of physical Education, 1998; 15: 29-33.

10. Gao B. Research on the somatotype features of Chinese elite male taekwondo athletes. Sport Science, 2001; 21: 58-61.

11. Heller J, Peric T, Dlouha R, Kohlikova E, Melichna J, Novakova H. Physiological profiles of male and female taekwondo (ITF) black. Journal of Sports Sciences, 1998; 16: 243-249.

12. Jagiełło W, Kalina R. Properties of motor development in young judokas. Journal of Human Kinetics, 2007; (17): 113-20.

13. Kazemi M, Waalen j, Morgan C. Profile of Olympic Taekwondo Competitors. Journal of Sports Science and Medicine, 2006; CSSI 14(3): 114-121.

14. Markovic G, Misigoj DM, Trninic S. Fitness profile of elite Croatian female taekwondo athletes. Collegium Antropologicum, 2005; 29: 93-99.

15. Melhim A. Aerobic and anaerobic power responses to the practice of Taekwondo. British Journal of Sport Medicine, 2001; 35(4): 231-34.

16. Newton RU, Kraemer WJ, Hakkinen K. Effects of ballistic training on preseason preparation of elite volleyball players. Medicine and Science in Sports and Exercise, 1999; 31(2): 323-30.

17. Pieter W. Talent Detection in Taekwondo Practitioners. Journal of Asian Martial Arts, 2010; 19(3): 9-29.

18. Sadowski J, Gierczuk D, Miller J. Success factors in elite WTF taekwondo competitors. Archives of Budo Science of Martial Arts and Extreme Sports, 2012; 2(3): 141-146.

19. Santos VGF, Franchini E, Lima-Silva AE. Relationship between attack and skipping in Taekwondo contests. Journal of Strength and Conditioning Research, 2011; 25(6): 1743-1751.

20. Taaffe D, Pieter W. Physical and physiological characteristics of elite taekwondo athletes. In: Commonwealth and International Conference Proceedings, Sport Science, Auckland, New Zealand, 1990; 3: 80-88. 
21. Tan B, Aziz AR, Chuan TK. Correlations between physiological parameters and performance in elite ten-pin bowlers. Journal of Science and Medicine in Sport, 2000; 3: 176-185.

22. Toskovic N, Blessing D, Williford H. Physiologic profile of recreational male and female novice and experienced tae kwon do practitioners. Journal of Sports Medicine and Physical Fitness, 2004; 44: 164-72.

23. Wąsik J. Structure of movement of a turning technique used in the event of special techniques in Taekwon-do ITF. Archives of
Budo Science of Martial Arts and Extreme Sports, 2009; 5: 11115

24. Yoon J. Physiological profiles of elite senior wrestlers. Sports Medicine, 2002; 32: 225-33.

25. Zar A, Gilani A, Ebrahim KH, Gorbani MH. A survey of the physical fitness of the male taekwondo athletes of the Iranian national team. Facta Universitatis. Physical Education and Sport, 2008; 6(1): 21-29. 